\title{
DESIGNING ORGANIZATIONAL
}

\section{INTERFACES}

Thomas W. Malone

90s: 85-009

\section{April 1985}

CISR WP \# 128

Sloan WP \# 1708-85

\section{- Association for Computing Machinery}

Permission to copy without fee all or part of this material is granted provided that the copies are not made or distributed for direct commercial advantage, the ACM copyright notice and the title of the publication and its date appear, and notice is given that copying is by permisiion of the Association for Computing Machinery. To copy otherwise, or to republish, requires a fee and/or specific permission

This paper appeared in the Proceedings of the $\mathrm{CHI}$ ' 85 Conference on Human Factors in Computing Systems (Sponsored by ACM/SIGCHI), San Francisco, CA, April 14-18, 1985.

Management in the 1990s

sloan School of Management Massachusetts Institute of Technology 


\title{
Management in the 1990s
}

Management in the 1990s is an industry and governmental agency supported research program. Its aim is to develop a better understanding of the managerial issues of the 1990s and how to deal most effectively with them, particularly as these issues revolve around anticipated advances in Information Technology.

Assisting the work of the Sloan School scholars with financial support and as working partners in research are:

\author{
American Express Company \\ Bellsouth Corporation \\ British Petroleum Company, p.I.c. \\ CIGNA Corporation \\ Digital Equipment Corporation \\ Eastman Kodak Company \\ Ernst \& Young \\ General Motors Corporation \\ International Computers Ltd. \\ $\mathrm{MCl}$ Communications Corporation \\ United States Army \\ United States Internal Revenue Service
}

The conclusions or opinions expressed in this paper are those of the author(s) and do not necessarily reflect the opinion of the Massachussetts Institute of Technology, the Management in the 1990s Research Program, or its sponsoring organizations.

\section{Acknowledgements}

Portions of this paper have appeared previously in Malone (1985) and Malone and Smith (1984).

The preparation of this paper was supported in part by Citibank, N.A., and by the Center for Information Systems Research, Sloan School of Management, Massachusetts Institute of Technology. Many of the original ideas for the intelligent mail filter system arose in discussions with Michael Cohen. I would also like to thank John Carroll and Michael Rothkopf for helpful comments. 
This paper argues that it will become increasingly important to extend our concept of user interfaces for individual users of computers to include organizational interfaces for groups of users. A number of suggestions are given for how to develop a theoretical base for designing such interfaces. For instance, examples are used to illustrate how traditional cognitive points of view can be extended to include information processing by multiple agents in organizations. Examples of design implications from other perspectives such as motivational, economic, and political are also included.

The field of human factors in computer systems has traditionally emphasized the analysis and design of user interfaces for individual users of computer systems. In this paper, I will argue that the analysis and design of what might be called organizational interfaces for groups of users will become increasingly important in this field, and I will suggest how we might go about developing theories to help in this endeavor.

\section{What is an "organizational interface"?}

The term "interface" was originally used in computer science to mean a connection between programs or program modules. It is now commonly used in the phrase "user interface" to include the connection with a human user as well. In the same spirit, I suggest that we can profitably extend this usage to include "organizational interfaces" as suggested by the following definitions:

user interface - the parts of a computer program that connect a human user to the capabilities provided by the computer;

organizational interface - the parts of a computer system that connect human users to each other and to the capabilities provided by computers.

Thus an organizational interface includes one or more user interfaces. Thinking of the problem in these new terms brings a number of additional factors into focus. For example, in designing traditional programs for word processing, the user interface is designed to facilitate separate problem-solving by isolated individuals. In designing programs for electronic mail, however, it is important to design an organizational interface that facilitates cooperative problem solving by groups of people. For instance, even a very "easy to use" electronic mail system that allows only explicitly named individual addressees will be much less useful in a large organization than one that includes some facilities for identifying people who might be interested in a message (e.g., centrally maintained distribution lists). 


\section{Examples of organizational interfaces}

Text sharing systems. One important class of systems in which organizational interfaces are critical is what I will call "text sharing systems." This class includes (1) electronic mail systems, (2) collaborative authoring systems that support two or more people jointly authoring a document, each with separate annotations, versions, and writing styles (e.g., Engelbart, 1984; Goldstein \& Bobrow, 1980), (3) computer conferencing systems in which it is easy for people to create new topics and subtopics and to add and delete themselves from topic interest lists (e.g., Hiltz \& Turoff, 1978; see also Sarin \& Grief, 1984), and (4) other structured systems that use links to represent the relationship between nodes of text stored in a common database (e.g., Trigg \& Weiser, 1984; Lowe, 1984).

Throughout this paper, I will use examples of text sharing systems to illustrate general points.

An intelligent mail filter. One particular kind of text sharing system I will use as an example is an "intelligent mail filter." It is a common experience in mature electronic mail communities for people to either (1) be overwhelmed with electronic "junk mail," or (2) develop restrictive social norms about where to send messages so that people sometimes fail to receive information they would have liked to see. To help solve this problem, we are now designing an intelligent mail filter to help people select the most useful pieces of electronic mail (or other semi-structured information) from a large pool of less useful "junk mail".

Previous approaches to this problem have been limited primarily to (1) centrally maintained "distribution lists" and (2) topic hierarchies in computer conferences. In later sections of this paper, I will suggest how concepts from artificial intelligence, economics, and organization theory can be used to develop more sophisticated ways of filtering information in organizations (c.f., Wilson et al, 1984; Denning, 1982).

Other examples. Other systems in which organizational interfaces are critical include: (1) various kinds of project management systems that keep track of who has commited to do what, automatically assign tasks to people, or monitor the use of various kinds of resources (e.g. , Sluizer \& Cashman, 1984; Kedzierski, 1982; Fox et al, 1983), and (3) different office procedure assistants and intelligent forms systems (Ellis, 1983; Croft \& Lefkowitz, 1984).

\section{Why will organizational interfaces become increasingly important?}

One of the most important reasons for the increasing importance of user interfaces appears to be the dramatic decrease in the cost of computer hardware. As computer hardware becomes cheaper, optimizing its use becomes less important and economizing on other resources, such as the time and effort of the people using it, becomes much more important. This same trend creates a pressure to make the use of existing computer applications more convenient for organizations as well as for individuals.

At the same time, whole new ranges of applications become economically feasible for a much larger number of people. We have already seen the beginnings of a flood of new computer applications for separate individuals using personal computers (e.g., word processing, spreadsheet manipulation, personal database retrieval). So far, 
these personal computers have seldom been connected to each other. The impending growth of local area networks and other telecommunications facilities, however, will enable a similar flood of interpersonal computer applications such as electronic mail, computer conferencing, and their successors.

\section{What kinds of theories will help in designing organizational interfaces?}

There is already a growing literature concerned with the relationship between organizations and computers (e.g. , see Keen \& Scott Morton, 1978; Kling, 1980; Zuboff, 1982; Markus, 1983). This literature has been concerned almost exclusively with two main themes: (1) the impacts of computers on organizations, and (2) the implementation of computers in organizations. In a few cases, the literature on impacts appears to recognize that the technology can have very different effects depending on how it is used, but all too often there seems to be an (often unstated) assumption of technological determinism and an exclusive focus on computer technology as it has been used, not as it might be used. The literature on implementation of computers pays somewhat more attention to different ways of using computer technology by emphasizing, for example, the importance of "user involvement" in the selection and the design of computer systems. Here, too, however, the most common approach has been to take the technology as being mostly predetermined and to focus on what leads people to use it. To caricature the two bodies of literature, the impacts literature has often seem to focus on "all the bad things that happen when you put in computers", and the implementation literature has seemed to focus on "how to get people to use computers, no matter how bad they are".

In contrast to both of these approaches, I suggest that we need to pay much more attention to how to design computer systems in the first place in such a way that they fit naturally into human organizations and have desirable impacts. In other words, I suggest that we need to focus much more on developing design theories, not just explanatory or predictive theories (e.g., see Simon, 1981). In addition to helping to design new computer systems, these theories may help design new organizational structures and processes, too.

Unlike explanatory theories ("Y because $X$ ") and predictive theories ("If $\mathrm{X}$, then $\mathrm{Y}^{\text {") }}$, design theories emphasize how to achieve goals ("In order to achieve Y, do X.") Thus design theories may include for example: (1) techniques for clarifying goals to be achieved by the systems (e.g., Sirbu, et al, 1984; Rockart, 1979), (2) taxonomies of actions that might help achieve goals (e.g. , Malone's (1982) taxonomy of user interface features that enhance enjoyableness), and (3) guidelines for selecting actions such as Norman's (1983) analysis of tradeoffs in user interface design and Malone and Smith's (1984) analysis of tradeoffs in organizational design.

\section{Theoretical perspectives on organizations}

There are a number of possible perspectives from which one can view organizations in order to develop design-oriented theories. Four of these perspectives appear repeatedly in the literature on organizations and computers (e.g., Kling, 1980; Keen \& Scott Morton, 1978): information processing, motivational, economic, and political. 


\section{Information processing perspective}

This perspective emphasizes the kinds of information used in an organization and how the information is communicated and processed. We might call this a "cognitive" perspective on organizations since it offers the prospect of extending a cognitive science approach to include, not just individual information processing, but also organizational information processing. Parts of this perspective have also been called "structural" (e.g., Galbraith, 1973) and "organizational communications" (e.g., Rice, 1980).

Cognitive science and artificial intelligence appear to have made important progress in the last two decades by identifying a level of analysis that is common to both human minds and computers: that is, the information processing necessary to do things such as solve problems, learn, and remember.

I believe that similar progress is now possible by extending this approach to include "organizational science," the analysis of the information processing necessary to coordinate the activities of separate agents, whether these agents are people or computers (see Cyert \& March, 1963; March \& Simon, 1958; Malone, 1982; Malone \& Smith, 1984; Malone, in press). This point of view unifies problems previously considered separately in fields such as computer science, organization theory, and economics. To illustrate this approach, I will discuss the implications of research in multi-agent problem solving and knowledge representation for designing textsharing systems.

Multi-agent problem solving and text-sharing systems. The topic of problem-solving has a long-standing and important place in the field of cognitive science (e.g., Newell \& Simon, 1972; Newell, 1980), but with few exceptions (e.g.., Smith \& Davis, 1981; Kornfeld \& Hewitt, 1981; Corkill \& Lesser, 1983) this work has only analyzed the problem-solving behavior of individual problem-solvers. One of the problems that emerges with multiple agent problem solving is how to control the explosion of messages that may arise when each agent broadcasts all results to all other agents.

The beginnings of a solution to this problem are suggested by the Hearsay II problem solving architecture (Erman et al, 1980). This architecture contains a number of separate modules called "knowledge sources" (KS"s) that communicate with each other through a global data structure called a "blackboard". Different KS's check the blackboard for situations they know how to respond to and then post the results of their computations back on the blackboard for other KS's to use. To prevent all KS's from having to scan the entire blackboard, the Hearsay II blackboard was carefully structured so that different regions corresponded to different parts of the problem being solved.

We can think of text sharing systems in human organizations as a similar kind of "electronic blackboard". For the problem domain of the original Hearsay system (speech recognition), a fairly simple two-dimensional structure was used for the blackboard (time vs. level of interpretation). For more complex problems in human organizations, we can use much more sophisticated structuring techniques such as semantic networks and frame inheritance networks (e.g., Brachman, in press).

For example, we expect the users of our intelligent mail filtering system to be able to conveniently compose messages using a network of different templates for different types of information (e.g., meeting announcements, bug reports). A meeting announcement template, for instance, would have fields for "time", "place", 
"organizer", and "topic". Its subtype, seminar announcement, would add a field for "speaker". Then receivers of messages will be able to construct much more sophisticated filters than would be possible with simple keyword searches (e.g., "show me all the announcements for seminars at MIT organized by people in my department except for seminars which occur on Tuesdays").

Different groups can develop detailed structures to represent the information of specific concern to them. For example, a product design team might have an elaborate network of message types describing different aspects of the product (e.g., market size estimates, response time specifications, alternative power supply vendors). Then, for instance, marketing specialists who believe that the critical factors determining potential market size for the product are cost and response time, can devote most of their attention to the regions of the blackboard in which people discuss those two factors and ignore all the rest of the technical specifications for the product.

\section{Motivational perspective}

The information processing perspective in the previous section captures many important aspects of coordinating the activities of people in organizations but it leaves out some of the most important factors about why people are there in the first place, how hard they work, and whether they find their activities satisfying or alienating (e.g., March \& Simon, 1958). This perspective is central to work in the "quality of work life" and "human relations" traditions (e.g., McGregor, 1960; Roethlisberger \& Dickson, 1939; Likert, 1961; Argyris, 1973; Herzberg, 1968).

Table 1 shows a number of factors that affect motivation and satisfaction at work (adapted from Malone \& Lepper, in press; and Hackman \& Oldham, 1980; see also Malone, in press). Some factors, such as pay, benefits, and working conditions, are primarily extrinsic to the tasks being performed.

Another set of factors are intrinsic to the tasks being performed and they seem to be particularly important in determining the degree of involvement and satisfaction in an activity (e.g., see Hertzberg, 1968). Malone (1982) discusses a number of suggestions for how intrinsically motivating factors like those found in computer games can be used to make user interfaces more interesting and enjoyable. When we expand our focus to include designing organizational interfaces, it becomes clear that computers make it possible and sometimes desirable to redesign whole jobs and organizations, as well as individual programs. For example, Hackman and Oldham's (1980) concept of "skill variety" in well-designed jobs can be seen as another way of increasing the challenge of a job.

One of the problems that may arise in text sharing systems like those we have been discussing is how to motivate people to contribute information. In addition to the pricing schemes discussed below, intrinsic motivations may be used for this purpose. For example, people's motivations for recognition by their peers might be engaged by a system in which rankings of the most widely read messages in different categories can be displayed along with their authors' names. This approach should be even more effective if messages that are rated by some readers as being very valuable are then automatically redistributed to a wider audience. 


\section{Economic perspective}

It is clear that issues of allocating resources are critical in organizations and it is these issues that are a central concern of the economic perspective on organizations.

Information economics. One possible use of economic concepts in a text sharing system is in designing various pricing incentives to control information flows. For example, Turoff (1984) describes a system that supports an internal "free market" for information and services within an organization. Certain kinds of information are highly desirable and employees who know (or have the skills to obtain) this information can sell the information or "contract out" some of their time to high bidders anywhere in the organization. On the other hand, the senders of unsolicited messages can be charged in proportion to the value of the time people will spend reading the messages, that is, more for long messages, more for messages sent to many people, and more for messages to highly paid recipients. In an even more extreme use of this idea, people who receive undesirable "junk mail" can indicate that fact and the sender will then be penalized by an additional surcharge.

Organizational structures. A different level of economic analysis can be used to assess the desirablity of alternative organizational structures (e.g., Marschak \& Radnor, 1972; Hurwicz, 1973). For example, certain kinds of activitives appear to be better coordinated by a hierarchical organization and others by a market organization (Williamson, 1975, Malone \& Smith, 1984). These theories can help determine what kinds of organizational structures information technology should encourage. For example, traditional management information systems can facilitate "vertical" information flows to enable centralized efficiency (e.g. , see Galbraith, 1973) while text sharing systems like we have been considering can facilitate "horizontal" information flows and enable decentralized flexibility (Malone \& Smith, 1984).

\section{Political perspective}

Even though many organizational and economic models assume, for purposes of simplicity, that all members of an organization have the same goals, it is a fact of daily organizational life that conflicts of interest between people are frequent and often of great importance to how well an organization functions (e.g., see Cyert \& March, 1963). Designers of organizational interfaces ignore this fact at their peril.

Coalition formation. Information technology can clearly affect the formation of coalitions in organizations. For example, IBM's "Gripe Net" (Emmett, 1981) was an electronic mail system that allowed a group of geographically separated programmers who felt that their software product was being given too little attention in the company's product line to develop a slightly mutinous sense of camaraderie and power.

Whether this particular coalition was good or bad for IBM, many observers of organizational behavior feel that the healthy formation of competing coalitions is an essential part of the functioning of organizations (e.g., Cyert \& March, 1963; Mintzberg, 1983). Lowe (1984) describes a system for computer-mediated debate that illustrates how a text sharing system might facilitate this process. In his system different people enter arguments, counter-arguments, and evidence into a highly structured textual data base in such a way that constructive debate is facilitated and newcomers are able to quickly see the most important opposing points of view. Our perspective here suggests that a system like this might be even more useful in 
facilitating coalition formation if it included the names (and electronic addresses) of the people who wrote and supported the views represented.

Confidentiality. There are already a number of techniques for specifying and enforcing various kinds of access controls in computer systems ( e.g., Saltzer \& Schroeder, 1975; Fernandez, Summers, \& Wood, 1981). The complexities of confidentiality in real organizations go far beyond the simple mechanisms proposed so far, however. Imagine, for instance, trying to decide whether to tell someone else in a company you work for about a serious problem in a system you are developing. You might consider factors like whether revealing the problem would hurt your reputation, how likely it is that the person could help you solve the problem, and what the consequences would be if you don't tell the person now and he finds out later. Though many of these factors would be quite difficult to represent, the more of them that can be automatically included in text sharing systems, the more useful the systems are likely to be.

\section{Conclusion}

Studies of people and computers have, in the past, fallen largely into two groups. On the one hand, there have been micro-level studies in the tradition of human factors and experimental psychology which have focused on how to design individual user interfaces that were easy for people to learn and use. On the other hand, there have been macro-level studies in the traditions of organization theory, economics, and other disciplines that have largely taken computer technology as predetermined and focused on what effects it had or how to get people to use it.

In this paper, I have tried to show how these two perspectives can be combined. I believe that we need to extend traditional cognitive points of view to include information-processing by multiple agents in organizations. At the same time, we need to develop political, motivational, and economic points of view that do not view computer technology as a "black box" but instead have positive implications for designing computer systems that fit naturally into human organizations. Table 2 summarizes a few implications of these different perspectives for designing one kind of organizational computer system: text sharing systems.

Designing these new "organizational interfaces" will not of course, be easy. But I believe that the directions I have suggested here will lead to strong theories to help in the task. Those who succeed in this task will lay the foundations, not only for commercial successes, but also for more satisfying and enjoyable lives for all of us who will live in the organizations of the next few decades. 
Table 1

Motivational Factors in Organizations

1. Extrinsic motivations

Pay, benefits, etc.

II. Intrinsic motivations

A. Individual

1. Challenge

2. Curiousity

3. Task meaningfulness

4. Autonomy

B. Interpersonal

1. Cooperation

2. Competition

3. Recognition

Table 2

Sample Implications of Different Theoretical Perspectives for Designing Text Sharing Systems

1. Information processing perspective

Semantic nets and similar techniques

for structuring shared information

Il. Motivational perspective

Wide dissemination of highly rated messages to engage recognition motivations

111. Economic perspective

Pricing schemes for controlling information flows

IV. Political perspective

Debate structures to facilitate coalition formation 


\section{References}

Argyris, C. Some limits of rational man organizational theory, Public Administration Review, 1973, 253-267.

Brachman, R. J. \& Schmolze, J. G. An overview of the KL-ONE Knowledge Representation System, Cognitive Science, in press.

Cyert, R.M. \& March, J.G. A behavioral theory of the firm. Englewood Cliffs, N.J.: Prentice-Hall, 1963.

Corkill, D.D. \& Lesser, V.R. The use of meta-level control for coordination in a distributed problem solving network. Proceedings of the International Joint Conference on Artifical Intelligence, 1983.

Croft, W. B. \& Lefkowitz, L. S. Task support in an office system. Technical report, Department of Computer and Information Science, University of Massachusetts, Amherst, MA, 1984.

Denning, P. J. Electronic junk. Communications of the ACM, 1982, 25, 163-165.

Emmet, R. VNET or Gripenet? Datamation, November 1981, 27, 48-58.

Engelbart, D.C. Collaboration support provisions in Augment. Proceedings of the AFIPS 1984 Office Automation Conference, Los Angeles, CA, February, 1984.

Erman, L.D., Hayes-Roth, F., Lesser, V. R., \& Reddy, D.R. The Hearsay-II speechunderstanding system: Integrating knowledge to resolve uncertainty. Computing Surveys, 1980, 12, 213-253.

Fox, M., Greenberg, M., Sathi, A., Mattis, J., \& Rychener, M. "Callisto: An Intelligent Project Management System." Technical Report, Intelligent Systems Laboratory, Robotics Institute, Carnegie Mellon University, Pittsburgh, PA, November 1983.

Fernandez, E., Summers, R., \& Wood, C. Database security and integrity. Reading, MA: Addison-Wesley, 1981 .

Galbraith, J. Designing complex organizations. Reading, MA: Addison-Wesley, 1973.

Goldstein, I. P. \& Bobrow, D. Descriptions for a programming environment. Proceedings of the lst Annual National Conference on Artificial Intelligence, Stanford, CA, August, 1980.

Hackman, J. R. \& Oldham, G.R. Work Redesign. Reading, MA: Addison-Wesley, 1980 .

Herzberg, F. One more time: How do you motivate employees. Harvard Business Review, January/February, 1968, 53-62. 
Hiltz, S. R. \& Turoff, M. The Network Nation: Human Communication via Computer. Reading, Mass.: Addison-Wesley, 1978.

Hurwicz, L. The design of resource allocation mechanisms. American Economic Review Papers and Proceedings, May 1973, 58, 1-30.

Kedzierski, B. "Communication and Management Support in System Development Environments." Proceedings of the Conference on Human Factors in Computer Systems, Gaithersburg, MD, March, 1982.

Keen, P.G.W. \& Scott Morton, M.S. Decision support systems: An organizational perspective. Reading, Mass.: Addison-Wesley, 1978.

Kling, R. Social analyses of computing: Theoretical perspectives in recent empirical research. Computing Surveys, 1980, 12, 61-110.

Kornfeld, W. A. \& Hewitt, C. The scientific community metaphor. IEEE Transactions on Systems, Man, and Cybernetics, 1981, SMC-11, 24-33.

Likert, R. New Patterns of Management. McGraw-Hill, 1961.

Lowe, D. "The Representation of Debate as a Basis for Information Storage and Retrieval." Unpublished Technical Report, Computer Science Dept., Stanford University, Stanford, CA January 1984.

Malone, T. W. Heuristics for designing enjoyable user interfaces: Lessons from computer games. Proceedings of the CHI Conference on Human Factors in Computer Systems, Gaithersburg, MD, March 15-17, 1982 (Reprinted in J. C. Thomas \& M. L. Schneider (Eds.) Human Factors in Computer Systems. Norwood, N.J. Ablex, 1984, pp. 1-12).

Malone, T. W. Organizing Information Processing Systems: Parallels between Human Organizations and Computer Systems. Xerox Palo Alto Research Center Working Paper, Palo Alto, CA, August, 1982.

Malone, T. W. Organizational interfaces. In J. Carroll (Ed.), Cognitive Aspects of Human Computer Interaction. Cambridge, MA: MIT Press, in press.

Malone, T. W. \& Lepper, M. R. Making learning fun: A taxonomy of intrinsic motivations for learning. In R. E. Snow \& M.J. Farr (Eds.), Aptitude, Learning, and Instruction III: Conative and Affective Process Analyses. Hillsdale, N.J.: Erlbaum, in press.

Malone, T. W. \& Smith, S.A. Tradeoffs in designing organizations: Implications for new forms of human organizations and computer systems. Massachusetts Institute of Technology, Center for Information Systems Resarch Working Paper \# 112, Sloan WP \# 1541-84, March 1984.

March, J. G. \& Simon, H. A. Organizations. New York: Wiley, 1958.

Markus, L. Power, politics, and MIS implementation. Communications of the ACM, June 1983, pp. 430-444. 
Marschak, J. \& Radner, R. Economic theory of teams. New Haven: Yale University Press, 1972.

McGregor, D. The Human Side of Enterprise. New York: McGraw-Hill, 1960.

Mintzberg, H. Power in and around organizations. Englewood Cliffs, N.J.: Prentice Hall, 1983.

Newell, A. Reasoning, Problem solving, and decision processes: The problem space as a fundamental category. In R. Nickerson (Ed.) Attention and Performance VIII, Hillsdale, N. J.: Erlbaum, 1980.

Newell, A. \& Simon, H.A. Human problem solving. $\quad$ Englewood Cliffs, N.J.: Prentice-Hall, 1972.

Norman, D. A. Design principles for human-computer interfaces. Proceedings of the CHI'83 Conference on Human Factors in Computing Systems, Boston, MA, December 12-15, 1983.

Pfeffer, J. Power in organizations. Marshfield, MA; Pitman, 1981.

Rice, R. E. Impacts of computer-mediated organizational and interpersonal communication. In M. Williams (Ed.) Annual Review of Information Science and Technology, White Plains, N.Y.: Knowledge Industry Publications, 1980.

Rockart, J.F. Chief executives define their own data needs. Harvard Business Review, March/April 1979.

Roethlisberger, F. J. \& Dickson, W. J. Management and the Worker: An Account of a Research Program Conducted by the Western Electric Company, Hawthorne Works, Chicago. Cambridge, Ma.: Harvard University Press, 1939.

Saltzer, J. \& Schroeder, M. The protection of information in computer systems. Proceedings of the IEEE, September 1975, 63, 1278-1308.

Sarin, S. K. and Greif, I. "Software for Interactive On-Line Conference." Proceedings of the ACM -SIGOA Conference on Office Information Systems, Toronto, Canada, June 1984.

Simon, H.A. The sciences of the artificial. Cambridge, MA: MIT Press, 1981.

Sirbu, M., Schoichet, S., Kunin, J.S., Hammer, M., \& Sutherland, J. OAM: An office analysis methodology. Behaviour and Information Technology, 1984, 3, 25-39.

Sluizer, S. and Cashman, P. "XCP: An Experimental Tool for Managing Cooperative Activity." Proceedings of the ACM Computer Science Conference, New Orleans, LA, March 1985.

Smith R. G. \& Davis, R. Frameworks for Cooperation in distributed problem solving. IEEE Transactions on Systems.Man, and Cybernetics, 1981, SMC-11, 61-69.

Trigg, R.H. , and Weiser, M. "TEXTNET: A Network-Based Approach to Text Handling." Unpublished Technical Report, Dept. of Computer Science, University of Maryland, College Park, MD, 1984. 
Turoff, M. Information, value, and the internal marketplace. N.J. Institute of Technology, Unpublished manuscript, September, 1983.

Williamson, O. E. Markets and hierarchies. New York: Free Press, 1975.

Wilson, P. A., Maude, T. I., Marshall, C. J., \& Heaton, N. O. The active mailbox-Your on-line secretary. Proceedings of the IFIP 6.5 Working Conference on Computer-based Message Services, Nottingham, England, North Holland Publications, 1984.

Zuboff, S. New worlds of computer-mediated work. Harvard Business Review, September-October 1982, 60, 142-152. 